\title{
Industrial tribology in the past, present and future: a review
}

\begin{abstract}
In the past 25 decades, natural sources have been absorbed with very high-speed, as a result our beloved planet is seriously damaged and contaminated. Tribology reinforced highly effective and high-speed equipment run by the power from coal and oil in the period with technological innovation of preserving power and components. Many types of sources reserves including those of power and components are being exhausted within one century. Revolutionary technologies of durability and zero-emission are being highly needed in the world sectors to determine new lifestyles of real health and durability for the everlasting living of humans and other resides in a symbiotic way. Tribology is predicted to build up its technological innovation for the needs in sectors and assistance a new industrial trend.
\end{abstract}

Keywords: tribology, technology, industry, energy, pollution, sustainability, zeroemission, revolution
Volume 5 Issue 3 - 202I

\author{
Md Shahinoor Alam \\ Department of Mechanical Engineering, Dhaka University of \\ Engineering and Technology, Bangladesh
}

Correspondence: Md Shahinoor Alam, PhD Research Student, Department of Mechanical Engineering, Dhaka University of Engineering and Technology, Gazipur-1707, Bangladesh, Tel +8801715009804, Email majshahin4282@gmail.com

Received: April 17, 202I | Published: May 06, 2021

\section{Introduction}

Since the beginning of Industrial Trend in 1700s in Great Britain, the speed and power of production apparatus have been improved step by step until the present time. Existing electric train with a speed around $300 \mathrm{~km} / \mathrm{hr}$ is one guide to show the speed rotation in the previous 250 years which was truly difficult to envision before modern upset. ${ }^{1,2}$ So, "mechanical and thermal severities of contact" and "chemical severities of contact" have gotten conspicuous in machine components in regards to relative movement. "Lubricants and theories of contact, friction and lubrication" have been created in the time frame to beat the severities and acknowledge dependable and productive transmission frameworks including bearings, pinion wheels and friction belts. "Wear laws" have been concentrated seriously over the most recent 50 years and hostile to wear materials and surface change techniques have been created for having higher unwavering quality and longer existence of production apparatus, and for higher productivity and profitability. ${ }^{1}$

The large monetary cooperation of protecting the costs of energy, segments and adjusting by diminishing friction and wear was checked and uncovered by the Jost Report (1966), which introduced another term of "Tribology" to portray the space of mechanical development of this character. It's thought and importance have been generally affirmed from that point and push forwarded in adaptable spaces of businesses. ${ }^{1-3}$ All areas are presently encountering to the significant marks of "Inadequacy of Sources Reserves" of energy and materials in next 50 years and the "Basic Pollutions" of air, water and ground. We are plainly expected to make mechanical advancement of "Sustainability, Maintainability and Zero-discharge" for the drawn out better ways of lives of all. ${ }^{2}$ Tribology is anticipated to advance the innovative difficulties through its exceptional way. Being the science and technology of the tribological aspects in the ecological balance and environmental impacts, green tribology can be used with the purpose of saving of energy and materials, as well as of enhancement of the environment and the quality of life. ${ }^{4}$ The modern tribology 4.0 to industry 4.0 can have in particular a big impact on the industrial needs to reduce losses and wastes, for instance with the development of new tribological components and materials also in connection with electronic smart systems and taking advantage of the information and communication technologies. ${ }^{5}$ At this setting this paper is planned at checking on the principal spaces of tribological achievement in the previous 25 decades and recommending its anticipated difficulties for the impending 50 years. In this paper, some major overall areas are examined concerning their endeavors to the family and worldwide commercial centers. Especially, the scope and impact of tribology in transport and electronic gadgets areas are referenced. Additionally, a perspective of how tribology is expected to prompt the future mechanical development of the world is given. At long last, a few thoughts on issues to be made plans to propel the condition of tribology in the commercial industries are advertised.

\section{Associate machinery/equipment and tribo- elements in previous 25 decades}

Necessary partner apparatus/gear and tribo-components are point by point sequentially arranged in Figure 1 where countless subtleties of names and years are from the book of "History of Tribology" are accommodated by D. Dowson (1979). ${ }^{6}$ From Figure 1 the advancement of tribological improvement in various instruments like smooth execution of steam motor, mechanical age of power, dependable execution of petroleum motors, turbines, fly motors with the created transmission frameworks in relationship with direction, pinion wheels and greases. For the present ventures and their items, bearings and pinion wheels greased up by oil are not all tribo-components but rather numerous others have been as of late planned like seals of gases and fluids, brakes and tires, electric wires and strips, attractive heads and tapes/plates, greaseless aides, oil-less dry metal cutting apparatuses, metal framing instruments, hip/knee joints and joints of robots in the space. The presentation of another word "Tribology" was opportune to portray the science and innovation for current businesses and the statements of "Space and aero-, Vehicle-, Process-, Informationstockpiling, Maintenance-, Bio-, Nano-, Eco, and Geo-tribology" have been presented over the most recent 50 years to describe the job of tribology in every trademark field of industry. ${ }^{1,2}$

\section{Empirical laws and theories of friction, lubrication and wear}

The experimental laws and hypotheses of friction, lubrication and wear set up in the time frame from 1470 to 2000 are recorded sequentially in Figure 2 along with the schematic graphs to show 
noticed qualities of friction, lubrication and wear. A great piece of data of names and years in the figure are from "History of Tribology" by D. Dowson (1979). ${ }^{1,6}$ This may be approved in the figure that the instrument of the exact friction laws saw by Leonardo da Vinci in 1470 were in fact portrayed with the theory of bond at real associations after around 500 years by F. Bowden and D. Tabor $(1954,1964)$ on the base of flexible contact idea of H. Hertz. ${ }^{7}$ The contact system was additionally evolved and portrayed by K.L. Johnson (1985) in his book. ${ }^{8}$ In examination, the standard knowing about components of film oil and the development of its idea were moderately effectively made in the time stretch from 1880 to 1970 start with the progressive works by B. Construction (1883) and O. Reynolds ${ }^{9,10}$ and a firm hypothetical stage for the plan of lubricated bearing and rotor was planned as demonstrated by D. Dowson and G.R. Higginson (1966), A. Cameron (1966) and Y. Hori (2006) in their books. ${ }^{11-13}$

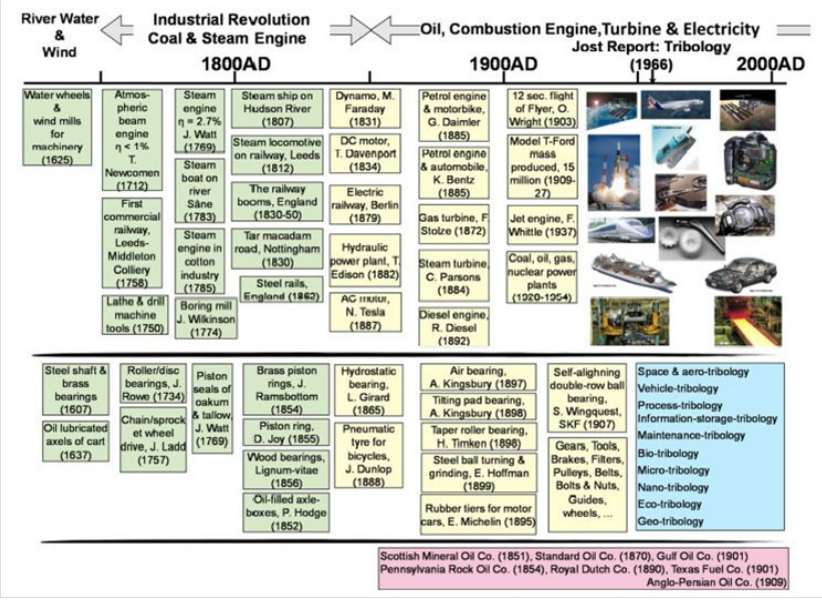

Figure I Representative machinery/equipment and tribo-elements introduced in the period of Industrial Revolution and oil age.

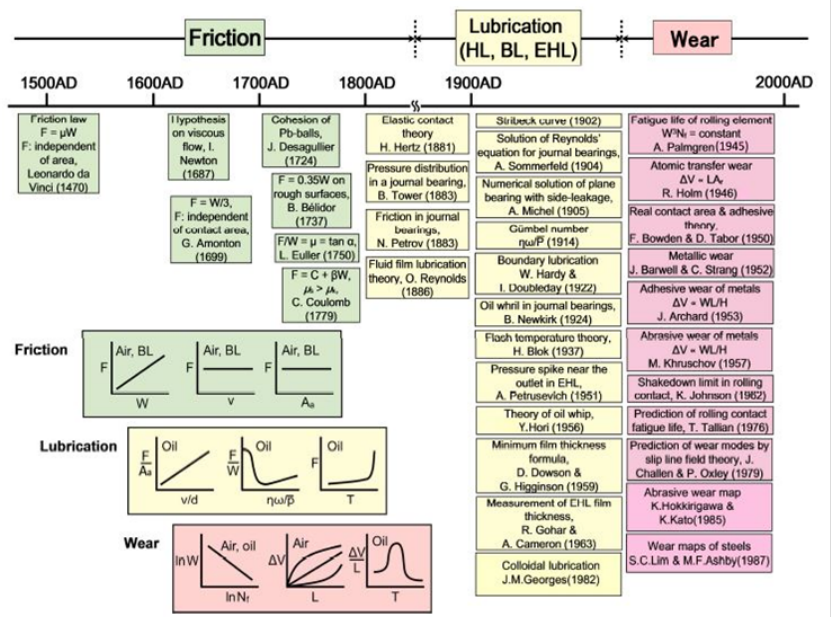

Figure 2 Empirical laws and theories of friction, lubrication and wear established in the past 550 years (F: friction force, W: load, v: velocity, Aa: apparent contact area, $\mathrm{d}$ : film thickness, $\eta$ : viscosity, $\omega$ : angular velocity, $\mathrm{p}$ : contact pressure, $\mathrm{T}$ : temperature, $\mathrm{N}_{\mathrm{f}}$ :fatigue limit cycle, $\Delta \mathrm{V}$ : wear volume, $\mathrm{L}$ : sliding distance).

The necessity of diminishing wear in industry got fundamental after 1920 as the severities of contact were very expanded under the more noteworthy requirements of severely lubricated or unlubricated friction enhancing more prominent soundness and longer life. Lubrication and wear were seriously examined as demonstrated by J.M. Georges (2000) in his book. ${ }^{14}$ Very basic wear laws were tentatively presented by A. Palmgren (1945), J. Archard (1953) and M. Khruschov (1957) until 1960 for regular metal parts and following investigation result was gathered in a handbook by M.B. Peterson and W.O. Winer (1980). ${ }^{13-18} \mathrm{~A}$ few wear ways were minutely all around saw with the SEM and wear diagrams were made by Lim SC \& Ashby $\mathrm{MF}^{17}$ Hokkirigawa K \& $\mathrm{Kato}^{18}$ \& Adachi et al. ${ }^{19} .{ }^{19-21}$ However, broad wear ideas are not yet all around perceived for the plan of contact materials and tribo-components.

\section{Examples of tribo-elements for modern machinery made in japan in the past 50 years}

Figure 3 sequentially shows 14 types of current machines and tribo-components manufactured in Japan in the previous 50 years. They are presented from the 50th Anniversary Report of Japanese Society of Tribologists (2007). ${ }^{22}$ The head/circle drive framework has been created in the accompanying 50 years for the more modest size and enormous limit. The control of friction and wear has facilitated electric train 'Shinkan-sen' run at over $270 \mathrm{~km} / \mathrm{hr}$. DLC surface treatment, ceramic bearing, oil-less tower connect bearing for nonCFC compressor were created in the timespan of 1970 to 1990 . Thrust bearing made of plastic of PTFE/GF/MoS2, Lead free over lay in driving/crank shaft were being created and utilized in 1994-1999. The DN esteem arrived at $3 \times 106$ with hybrid ceramic orientation for a rocket motor in 2001 and $5 \times 106$ for a machine axle in 2004. These fruitful accomplishments in enterprises are made conceivable by the principal information on properties of friction and wear at the dry or greased up contact interface appeared in Figure 2. ${ }^{1}$

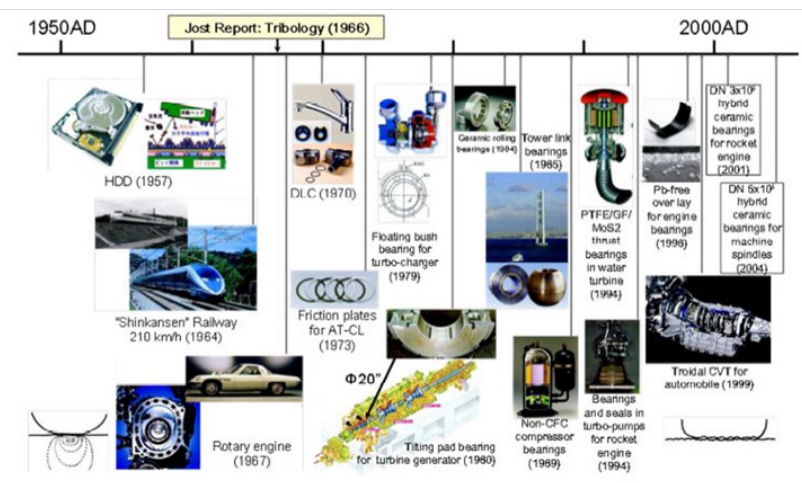

Figure 3 Examples of machinery and tribo-elements made in Japan in the past 50 years (2007).

\section{Lubricant, transportation and electronics industry in Korea}

The principal part of Korean modern tribology relies upon improving lubes. The lubing market began to show up in the 1960's along with the monetary development plan set out by the govt. Around then, a large part of the oil items were procured from abroad. An enormous piece of grease and lube was utilized for vehicles and gear for developing the streets until the mid1970's. During that time as the Korean business moved to enormous, shipbuilding, and vehicle areas in the later part of 1970's and 1980's, the requirement for lube oil expanded rapidly. In one way, well known necessity for oil might be considered as the development in manufacturing industrial items. Figure 4 shows the production of lube oil in The Korea from 1995 to $2005 .^{23}$ The fall in the oil manufacturing in 1998 is connected to the IMF monetary issues that The Korea faced in 1997. Diminishing 
trend all through the monetary framework is very much appeared in the necessity for oil. This affinity can be additionally visualized from assessment of the oil manufacturing with the GDP variations appeared in Figure $5 .{ }^{24}$ The general example of the GDP follows that of the lube producing. Along these lines, development in lubrication production might be considered as one of the indications of the condition of financial trend.

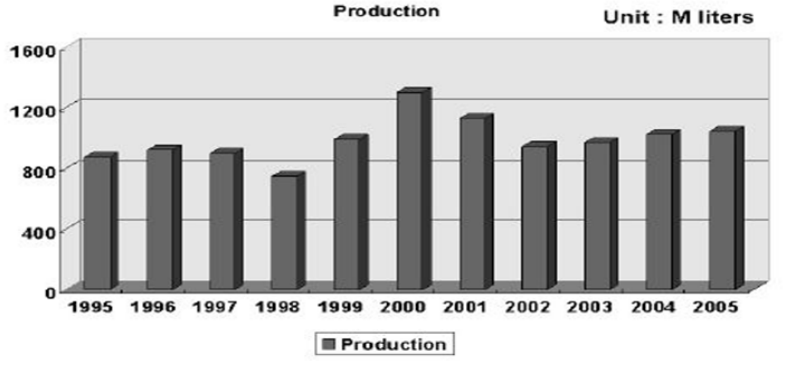

Figure 4 Lubricant production in Korea from 1995 to 2005.

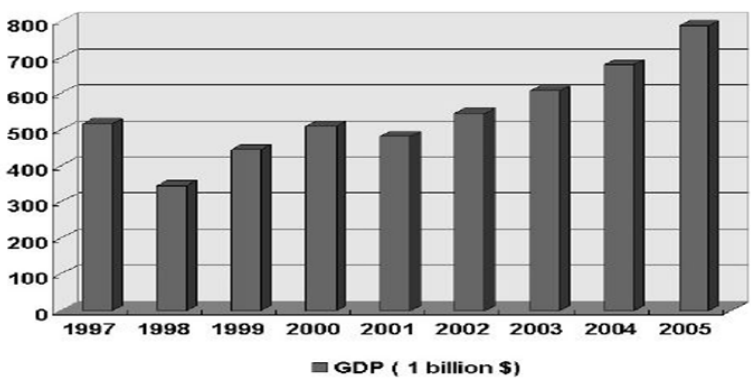

Figure 5 GDP of Korea from 1997 to 2005.

Korean vehicle business represents around $10 \%$ of the country's absolute exchange, and henceforth, it is one of the greatest and most significant areas in Korea. Korea produced 1.8 million vehicles while trading just 30,000 of it in outside of the country in $2003 .{ }^{25}$ This has been significantly realized previously, there are various tribological issues that face the vehicle industry. Autos are loaded with moving zones that should be improved from the tribological point of view to get desired quality products. Indeed, the majority of the vehicle regions that require overhauling are territories that are dependent upon friction and wear. The tribological worries shared by vehicle organizations in Korea are almost normal all throughout the planet. Especially, surface finishing procedures to acquire ideal moving conditions to reduce alteration and sound are being continuously researched. The fundamental idea for finishing the surface is represented in Figure $6 .{ }^{26}$ The reason for the surface is to give better finishing conditions at the interface and furthermore wipe out wear particles that may cause the furrowing segment of grating to increment. ${ }^{27}$ This subject has also got enormous initiative to other similar fields. These other tribological advancements incorporate functional oil added substances, continuously variable transmission, brake screech counteraction, and numerous others that include contacts. ${ }^{26}$ In recent past, railroad tribology in Korea has acquired a lot of interest with the reception of fast train in 2004. The public authority intends to build up a cutting edge high velocity train that can go at a speed of $400 \mathrm{~km} / \mathrm{h}$ by $2011 .{ }^{28}$ The wheel/rail communication and wear issues, contact and wear of pantograph, emergency braking technology, and brake wear are a portion of the tribological issues investigated in the high velocity train innovation.

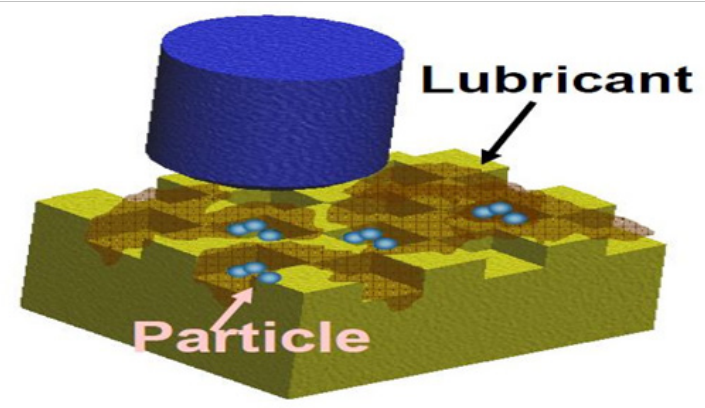

Figure 6 Purpose of textured surface is to improve the lubrication condition as well as to eliminate the wear particles at the sliding interface.

The Korean gadgets industry has especially built a solid foundation in the semiconductor memory sector. It represents about a similar earning rate as the auto business. Semiconductor memory trade sum is in excess of multiple times the measure of total import. But the import of non-memory semiconductor gadgets is marginally higher than that of export. ${ }^{25}$ The tribological issues identified with semiconductor are generally experienced during the production cycle. Chemical Mechanical Polishing (CMP) process for planarization of wafers includes fragile grating and substance communications among the slurry, cushion, and the wafer. The cycle control boundaries are straightforwardly identified with frictional and grating collaborations, which thus direct the result of the interaction. The major question is to decrease the quantity of CMP process during wafer handling to limit the chance of cycle mistake and time. ${ }^{26}$ Another significant key gadget of Korea that includes critical tribology is the printer. At present, multiwork inkjet printers have the biggest market among the printers. The vital part of an inkjet printer is the printer head which has a miniature spout through which the ink is shot out onto the paper. Tribological study of this gadget includes the miniature slender activity of the ink which is straightforwardly identified with the surface energy and the wetting qualities of the spout channel. ${ }^{26}$ Perhaps the most complex and sensitive utilizations of tribology is the data stockpiling gadget. Korean gadgets industries represent a critical part of the world's optical and attractive stockpiling gadgets. The advancement of a nanometer thick carbon jacket, improvement of HDI for perpendicular magnetic media, movable flying height, and thermal assisted recording are few of the main points of interest including tribology of current and near future hard disc drive innovation.

\section{Tribology for savings and better functions}

Table 1 projects the commercial savings of modern investment funds in UK (1965) by tribology in seven classifications as appeared in the Jost Report. ${ }^{3}$ The saving funds in classes of (a), (b) and (c) can be accomplished mostly by minimizing wear and those in classifications of (d) and (e) by diminishing friction. Those profits are made by the upgrades in "Security, Safety, Reliability and Efficiency" of machines and equipment through the decrease in wear and friction technology. The financial commitment of this sort by tribology can be by and large saw in any sort of hardware including cars, airplanes, rail ways, power plants and manufacturing industries. Different studies done in Canada, China, Germany, Japan, UK and USA presumed that putting resources into tribology could set aside to $1.4 \%$ of GDP. The other sort of commitment by tribology is to give helpful capacities to raise the utility value of machines hardware. Use of friction plate with automatic transmission and traction disc with variable transmission as in Figure 3 are instances of this sort. Those two sorts of transmissions 
are worked by friction at the contacts of rubbing plates or traction disks where high grating is needed for the high productivity of force transmission. High friction is the fundamental property at such contact interfaces for giving the capacity of force transmission to the system framework. ${ }^{1}$ Crushing and cleaning for smoothing surfaces, friction welding for joining components, scouring for controlling fluid precious stones and bolts/nuts for fixing components make the comparative sort of commitment of giving fundamental capacities to components and apparatus by tribology, where low grating and low wear are not really needed. ${ }^{1}$ Although they are not clear in Figure 3 , their tribological commitments of giving vital key capacities to components are vital in industry for acknowledging new or improved exhibitions of apparatus, as appeared in the Figure $7 .^{1}$

\begin{tabular}{|c|c|c|c|}
\hline & & iillion $\varepsilon$ ) & ( $\%$ in Sum) \\
\hline (a) & $\begin{array}{l}\text { Savings in maintenance } \\
\text { and replacement costs }\end{array}$ & 230 & 45 \\
\hline (b) & $\begin{array}{l}\text { Savings on losses } \\
\text { consequential upon breakdown }\end{array}$ & 115 & 22 \\
\hline (c) & $\begin{array}{l}\text { Savings in investment } \\
\text { through increased life of machinery }\end{array}$ & 100 & 19 \\
\hline (d) & $\begin{array}{l}\text { Reduction in consumption } \\
\text { through lower friction }\end{array}$ & 28 & 5 \\
\hline (e) & $\begin{array}{l}\text { Savings in investment } \\
\text { due to higher utilization ratios } \\
\text { and greater mechanical efficiency }\end{array}$ & 22 & 4 \\
\hline (f) & Reduction in manpower & 10 & 2 \\
\hline (g) & Savings in lubricant costs & 10 & 2 \\
\hline
\end{tabular}

Figure 7 Industrial savings by tribology in UK (1965) from the Jost Report (1966).

\section{Technical tasks in the age of depletion of resources reserves and the environmental pollution}

Energy has been totally accommodated the existence of people from oil and petroleum product and adequate mineral by profoundly compelling investigation in the previous 250 years. Figure 8 uncovers the accessible occasions of sources supplies of energy and metals later on with the speed of admission during 2009 (Ministry of Environment Government of Asia, 2011 and BP Mathematical Review, 2011). ${ }^{29,30}$ It is obvious from the figure that new techniques for acquiring energy from inexhaustible sources and of utilizing metals over and again without discarding must be created within 50 years. Reproducible materials will get essential for shaping components and apparatus. ${ }^{1}$ Figure 8 shows the consequences of mathematical reproductions of the measure of regular assets, food per capita, industrial production per capita, contamination/(contamination in 1970) and populace on the planet by D. H. Medows, et al. (1972). ${ }^{31}$ The strong graph of "assets" in the figure partially represents the graph in Figure 9 and depicts the fast exhaustion of characteristic of assets on the earth within 50 years. The strong line of "contamination" shows incredibly fast expansion in them brought about by the quick utilization of the regular assets and broad discharges of dirty side-effects to air, water and soil. As the consequence of such consumption in regular assets and matched expansion in contamination, the measure of mechanical yield and that of food on the planet will out of nowhere drop before 2050 in the wake of encountering their pinnacles, which will be comparably trailed by the total populace. ${ }^{1}$ The realities appeared in Figure 8 and expectations appeared in Figure 8 reveal to us the solid and critical necessities of new innovations accessible to live without regular assets and contaminations in the climate. Diminishing the measure of outflows of carbon dioxide revealed by IPCC (2007) is an average model requiring speedy advancement of new innovations in the perspective of worldwide warming. ${ }^{32}$

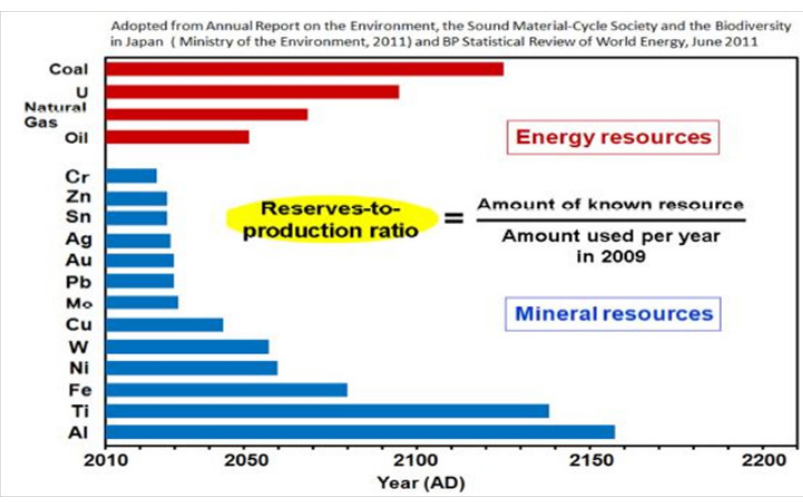

Figure 8 Resources reserves of energy and metals. (Ministry of the Environment, 20I I) and (BP Statistical Review, 20I I).

Specialized upsets are fundamental in enterprises for the utilization of sustainable power and reused and reproduced materials without hurtful outflows to the climate. Tribology is relied upon to play its job in such specialized transformations. ${ }^{1}$ Because the goal and essence of tribology specially the green tribology is to save material resources, improve energy efficiency, decrease emissions, shock absorption, investigate and apply novel natural bio- and eco-lubricants as well as to reduce the harmful effects of technical systems on the environment, and consequently, improve the quality of human life. ${ }^{33}$

\section{Revolutions in energy, materials \& environment and design demands in 2000- 2100}

People are currently at happens of altering their lifestyle from existing ones of "Large scale manufacturing, Mass-utilization and Throw-away" to the new horizon of life of no organic sources of energy and food staffs, as demonstrated in Figure 8 \& Figure 9. They also must be prepared for the unfavorable consequences for their wellbeing and prosperity by the accumulated tainting in air, mineral water and ground. Substance debased dinners and climatic change are outlines of the unfavorable impacts. Difficulties to make upsets in innovations of energy, materials and climate are obviously needed for tackling the issues and setting up new "Lifestyle of Health and Sustainability (LOHAS)" depicted by P. H. Ray and S. R. Anderson ${ }^{34}$ which would guarantee the never-ending presence of mankinds in cooperative associations with other living things. ${ }^{1}$ Figure 10 records the fundamental watchwords to portray those revolutions. "Energy revolution" will be made by changing wellsprings of energy from oil, gas, uranium and coal to reproducible energy like the sun, water, wind, ground heat and bio-mass. Table 3 records fundamental catchphrases identified with the items in 2000-2100. To plan items for the prerequisite, "Designing" of sustainable power, reusing, reuse and multiplication of materials, zero-emanation of contaminations and biological equilibrium should be developed. In deciding the expense of an item, expenses of reusing or potentially recreating materials should be thought of. LCA (Life Cycle Assessment) in 2000-2050 will basically manage the things in Figure 11 for supportability and cost, where tribology is required to make commitments from the perspective of LCT (Life Cycle Tribology) for the better score of LCA of an item (Kato and Ito, 2004, 2005). ${ }^{35}$

In Figure 12, the three white arrows schematically show the tribologically created upgrades of wellbeing and supportability, cost-saving and an incentive for one item. It would be significant for 
conventional tribologists to consider potential methods of tribology to build the upgrades later on by presenting new tribological ideas and approaches in the period of unrests of energy, materials and climate. As the humanity progresses, tribology continue to make vital contributions in addressing the demands for advanced technological developments, resulting in, for example, reducing the fuel consumption and greenhouse gases emission, increasing machine durability and improving the quality of life through artificial implants, among the others. ${ }^{36}$

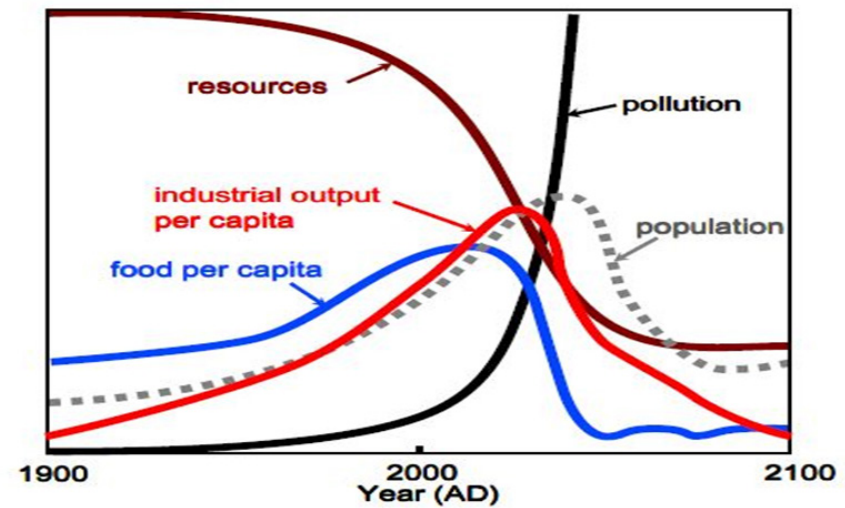

Figure 9 Numerical simulations of the natural resources.

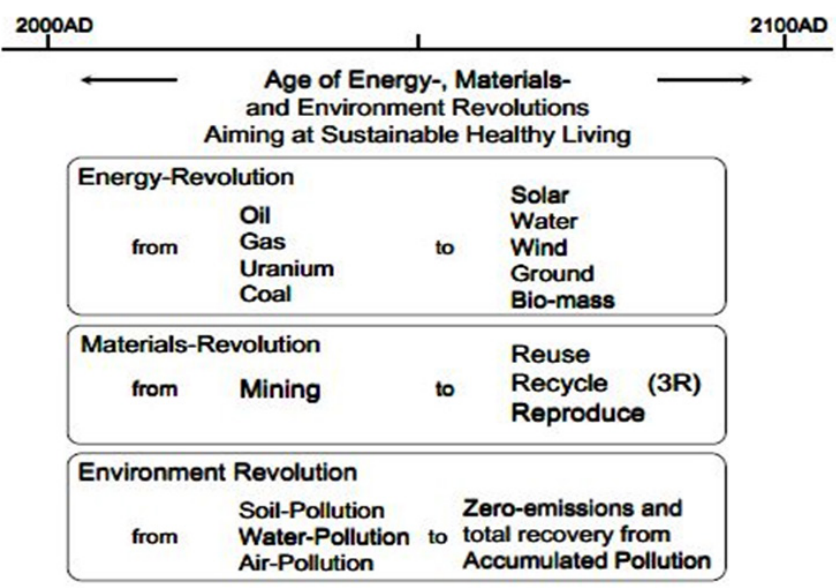

Figure 10 Keywords to describe energy, materials, and environment revolutions in 2000-2100 AD.

\section{Future industrial tribology}

Tribology has been an essential piece of mechanical advancement up to now. As the accentuation of innovation step by step extends to bio and nanotechnology, the part of tribology is required to be more prominent than any time in recent memory. Among the specifications used in industry in the Twenty first millennium, sturdiness will turn into a fundamental one which has not been truly thought to be in the last thousand years. The major tribological methods with the possibility of strength are described in Figure 13, which should turning out to be reality in 2000-2050. The search queries in the table are "light segments, coated areas, nano-design, control of wear foreign substances and outgases, reproducible lube oils, deliberately running-in, and on-request lube oil."

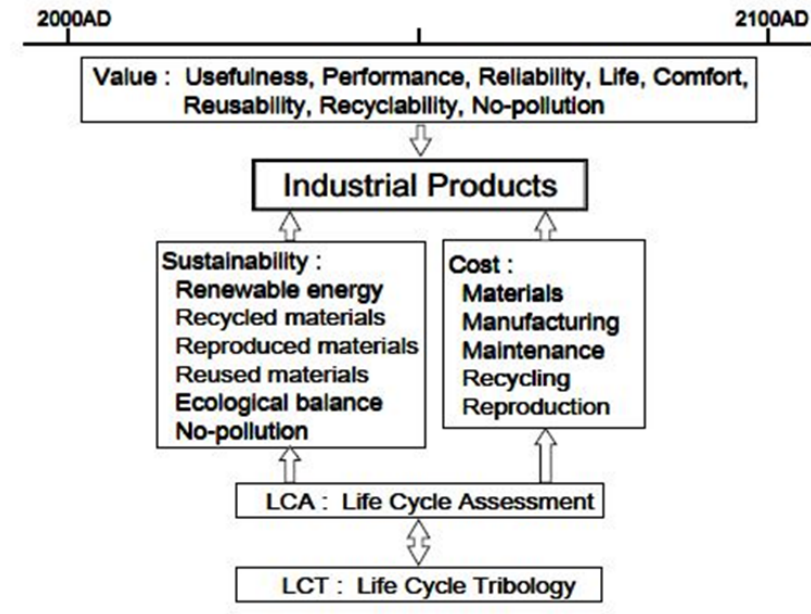

Figure II Design demands of industrial products in 2000-2 100 AD'

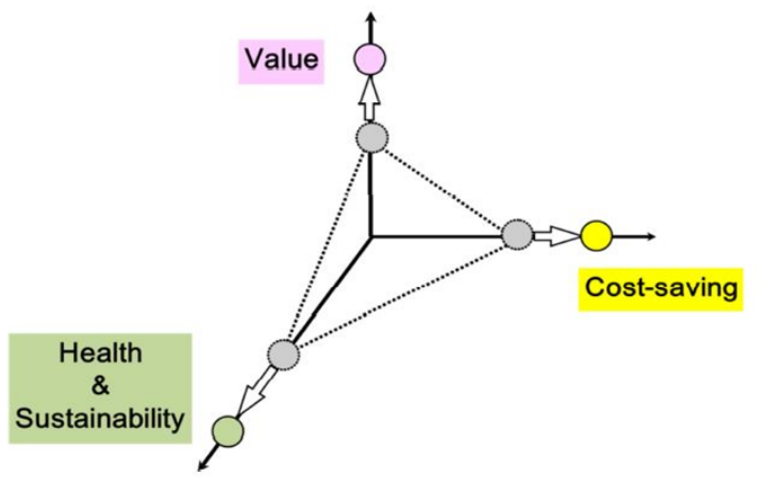

Figure 12 Schematic diagram describing the tribologically generated improvements of value, cost-saving and health \& sustainability of a product with the three white arrows.

\begin{tabular}{|c|c|c|}
\hline & $\begin{array}{l}\text { Heavy tribo-elements of } \\
\text { metals }\end{array}$ & $\Rightarrow \begin{array}{l}\Rightarrow \text { Light tribo-elements of } \\
\text { reproducible materials }\end{array}$ \\
\hline & $\begin{array}{l}\text { Bulk materials for contact } \\
\text { surfaces }\end{array}$ & $\Rightarrow$ Coated surfaces for contacts \\
\hline & $\begin{array}{l}\text { "mm" to " } \mu \mathrm{m} \text { " scale surface } \\
\text { design }\end{array}$ & $\Rightarrow+$ nano-scale surface design \\
\hline & $\begin{array}{l}\text { No control of wear particles } \\
\text { and tribo-outgases }\end{array}$ & $\Rightarrow \begin{array}{l}\text { On-purpose control of wear } \\
\text { particles and tribo-outgases }\end{array}$ \\
\hline & Mineral oil lubricatants & $\begin{array}{l}\Rightarrow \text { Reproducible oils, water, } \\
\text { gases, complex emulsions }\end{array}$ \\
\hline \multicolumn{3}{|c|}{ (6) Resultant running-in surfaces $\Rightarrow$ On-purpose running-in surfaces } \\
\hline (7) & Over-supply of lubricant & $\Rightarrow \begin{array}{l}\text { Minimum supply of lubricant on } \\
\text { demand }\end{array}$ \\
\hline
\end{tabular}

Figure 13 Tribological approaches for sustainability.

\section{Conclusion}

Since the beginning of mechanical upset in 1750 , the speed and power of industrial apparatus have been immediately improved as of recently. The innovation for overseeing grating or scouring have been grounded to help such modern requirements in 1750-2000 by making tribo-components, lubes, oiling strategies and oil idea. Controlling measure became one more significant theme in different mechanical regions particularly after 1950 . Extreme segments, ceramics and hard covers have been planned as against wear segments. Wear diagrams were introduced to separate different wear modes. In any case, wear 
ideas are not yet pleasantly made to give plan necessities for wear control. There are some all-around affirmed observational laws of friction, wear and fluid film lubrication. Mechanical, chemical substance and tribo-chemical methodologies have been made to comprehend those observational laws. The watchwords of genuine contact region, adhesion, stiction, shake-down, fluid film, limit layer, tribolayer, and fatigue-, abrasive- , adhesive- , and corrosive- wear have been acquainted and well utilized to describe noticed behavior. The Stribeck curve and wear map have become standard approaches to portray noticed properties of friction and wear. In the 21st Century, tribologists are looking to a major difference in industry which will be called as "The third Industrial Revolution (J. Rifkin, 2011) ${ }^{37}$ after "The second and first Industrial Revolutions." Figure 14 sums up fundamental catchphrases to depict them are corresponding to the measures of normal assets and natural contamination. It is deduced in the figure that individuals in this century will give high worth to the "Lifestyle of Health and Sustainability (LOHAS)" and leave the current ways of life of large scale manufacturing, mass-utilization and discard. In the third Industrial Revolution, reproducible energy and elements will make its foundation like metal, petroleum derivative and oil set up of the plots for the first and second Industrial Revolutions. The financial move will be made by the spirit of decentralization, collaboration and two-ways on the globe, which is portrayed as a horizontal kind of development of industry. In the first and second Industrial Revolutions, it was taken by the arrangement of centralization and top-down ordinarily approaches, which is depicted as a vertical kind. It should be important for existing tribologists to appreciate such worldwide changes of industry from the customary viewpoint and discover contributive methods of tribo-technological development for next 50 years. Catchphrases for such challenges are "Health and Sustainability"

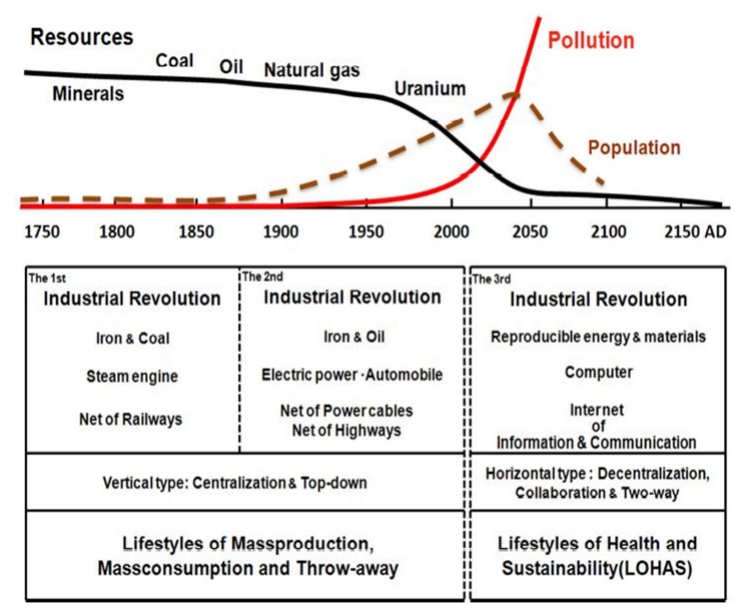

Figure 14 Key words to describe industrial revolution in relation to the amounts of natural resources and environmental pollution.

\section{Acknowledgments}

None.

\section{Conflicts of interest}

The author declares that there is no conflict of interest.

\section{References}

1. KATO Koji. Tribology in the past and future. Mechanical Engineering Reviews. 2014;1(1):DSM0008-DSM0008.
2. Kato Koji. Industrial tribology in the past and future. Tribology online. 2011;6(1):1-9.

3. Jost PH. A Report on the Present Position and Industry's Needs (HMSO). UK Department of Education and Science; 1966.

4. Assenova E, Majstorovic V, Vencl A, et al. Green Tribology and Quality of Life. International Convention on Quality-ICQ, Belgrade. 2012.

5. Ciulli E. Tribology and Industry: From the Origins to 4.0.Front. Mech Eng. 2019;5:55.

6. Dowson D. History of Tribology. Longman, London \& New York. 1979.

7. Bowden FP, Tabor D. Friction and Lubrication of Solids. London. Oxford University Press; 1954, 1964.

8. Johnson KL. Contact Mechanics. Cambridge University Press; 1985.

9. Tower B. $1^{\text {st }}$ report on friction experiments. Proc Inst Mech Eng Nov. 1883:632-666.

10. Reynolds O. On the theory of lubrication and its application to Mr. Beauchamp Tower's experiments including an experimental determination of the viscosity of olive oil. Phil Trans. 1886;177:157234

11. Dowson D, Higginson GR. Elasto-Hydrodynamic Lubrication. Pergman. 1966.

12. Cameron A. The Principles of Lubrication. Longmans. 1966.

13. Hori Y. Hydrodynamic Lubrication. Springer; 2006.

14. Georges JM. Frottement, usure et lubrication, Eyrolles. 2000.

15. Palmgren A. Ball and Roller Bearing Engineering. Philadelphia. SKF; 1945.

16. Archard J. Contact and rubbing of flat surfaces. J Appl Phys. $1953 ; 24: 981-988$

17. Khruschov M. Resistance of metals to wear by abrasion-as related to hardness. Proc Int Conf on Lubrication and Wear Inst Mech Engr; London. 1957. p. 655-659.

18. Peterson MB, Winer WO. Wear Control Handbook. ASME; 1980

19. Lim SC, Ashby MF. Wear-mechanism maps. Acta Metall. 1987;35(1):124.

20. Hokkirigawa $\mathrm{K}$, Kato K. An experimental and theoretical investigation of ploughing, cutting and wedge formation during abrasive wear. Tribology International. 1988;21(1):51-57.

21. Adachi K, Kato K, Chen N. Wear map of ceramics. Wear. 1997;203204:291-301.

22. $50^{\text {th }}$ Anniversary Report of Japanese Society of Tribologists. 2007.

23. Korea National Statistical Office. 2006.

24. Major Economic Statistics, Korea Ministry of Foreign Affairs and Trade. 2006.

25. Ministry of Commerce, Industry, and Energy. 2006.

26. Kim Dae-Eun. Industrial Tribology in Korea: Past, Present and Near Future. Tribology Online 2.1. 2007:5-9.

27. Hwang DH, Kim DE, Lee SJ. Influence of Wear Particle Interaction in the Sliding Interface on Friction of Metals. Wear. 1999;225:427-439.

28. Maeil Business News. 2006.

29. Ministry of the Environment Government of Japan. Annual Report on the Environment, the Sound Material-Cycle Society and the Biodiversity in Japan 2011. 2011. 
30. BP Statistical Review. BP Statistical Review of World Energy June 2011. BP Global homepage.

31. Medows DH, Medows DL, Randers J, et al. The Limits to Growth. New York. Universe Books; 1972.

32. IPCC, 2007: Climate Change: Synthesis Report. Contribution of Working Groups I, II and III to the Fourth Assessment Report of the Intergovernmental Panel on Climate Change Team. Pachauri, Reisinger RK, editor. Geneva, Switzerland. IPCC; 2007. p. 104.

33. Nguyen VN, Kuzharov A, Ninh LH, et al. 'Green Tribology', Tribology. Intechopen. 2020:1-20.
34. Ray PH, Anderson SR. The Cultural Creatives. USA. Harmony Books; 2000.

35. Kato K, Ito K. Modern tribology in life cycle assessment. In: Dowson D, Editor. Proc. 31st Leeds-Lyon Symposium on Tribology; Leeds, 2004, Tribology and Interface Engineering Series; Elsevier; 2005(48):495506.

36. Gwidon WS. How tribology has been helping us to advance and to survive. Friction. 2017;5(3):233-247.

37. Rifkin J. The Third Industrial Revolution. Palgrave Macmillan. 2011. 